\author{
Proceedings of the $9^{\text {th }}$ International Conference on Applied Informatics \\ Eger, Hungary, January 29-February 1, 2014. Vol. 2. pp. 327-327 \\ doi: 10.14794/ICAI.9.2014.2.327
}

\title{
New way to use information technologies to monitor spatial abilities*
}

\author{
Nikoletta Ekker \\ Faculty of Informatics, Eötvös Loránd University \\ ekkern@inf.elte.hu
}

\begin{abstract}
The 3D applications, as well as virtual environments (VEs) are spreading faster and faster all around the world. It has been proved that these developments play an important role in navigation training. Among the firsts, Witmer and his colleagues [1] demonstrated in their study that a well-developed $\mathrm{VE}$ could be an effective tool for route learning.

Our research goal is to respond to the questions of how those kinds of applications should be developed for a better understanding and mapping the cognitive processes and how panoramic pictures could be involved in this field. Thus, we created a Virtual Panoramic Environment (VPE), and in the experimental task, participants were asked to navigate in a virtual building and solve three subtasks on every occasion.

The execution time values present that the participants were able to achieve progressively better results during the experiment. Future research will need to compare the performance in VPE and in the original 3D VE navigating in "First Person View" mode.
\end{abstract}

Keywords: virtual environments, panoramic pictures, navigation

MSC: $68 \mathrm{U} 99$

\section{References}

[1] B. G. Witmer, J. H. Baily, B. W. Knerr: Training Dismounted Soldiers in Virtual Environments: Route Learning and Transfer, U.S. Army Research Institute for the Behavioral and Social Sciences (1995)

*The research was carried out as part of the EITKIC_12-1-2012-0001 project, which is supported by the Hungarian Government, managed by the National Development Agency, financed by the Research and Technology Innovation Fund and was performed in cooperation with the EIT ICT Labs Budapest Associate Partner Group (www.ictlabs.elte.hu). I also wish to acknowledge the support of Dr. Márta Turcsányi-Szabó and Dr. András Lórincz. 